\title{
Significados da Ressocialização para Agentes Penitenciárias em uma Prisão Feminina: Entre o Cuidado e o Controle
}

\author{
Mariana Barcinski ${ }^{1}$ \\ Sabrina Daiana Cúnico \\ Marina Valentim Brasil \\ Pontifícia Universidade Católica do Rio Grande do Sul, Porto Alegre, RS, Brasil
}

\begin{abstract}
Resumo
O presente estudo objetivou investigar a percepção de uma agente penitenciária acerca de suas atribuições, especialmente sobre o seu papel como co-participante em processos de ressocialização de mulheres privadas de liberdade. Através da Análise Crítica do Discurso de uma entrevista semiestruturada, identificou-se significados contraditórios atribuídos por esta agente ao processo de ressocialização. Ao explicitar as especificidades do seu dia-a-dia de trabalho, os sentidos da ressocialização e a responsabilidade frente ao processo ressocializador foram construídos discursivamente pela entrevistada. Tal responsabilidade foi por vezes entendida como inerente ao trabalho do agente penitenciário e em outras foi identificada como exclusivamente das mulheres encarceradas. Embora a partir de uma crítica incipiente, um terceiro aspecto foi apontado pela agente como determinante das possibilidades de ressocialização das presas: a questão social e o contexto socioeconômico de onde as mulheres são provenientes. Embora tal crítica não tenha sido aprofundada no discurso da participante, entendemos que o fracasso ou as dificuldades inerentes ao processo ressocializador deva também ser creditado a uma estrutura social que obstaculiza as possibilidades reais de reinserção social. Portanto, ressocializar seria simultaneamente o resultado de esforços pessoais (das presas e das agentes) e de uma configuração social mais justa e igualitária.
\end{abstract}

Palavras-chaves: Ressocialização, instituição prisional feminina, agentes penitenciárias.

\section{The Meanings of Re-Socialization to Correctional Officers in a Women's Prison: Between Care and Control}

\begin{abstract}
The present study aimed at investigating a correctional officer's perception of her duties, specially with regard to her role as co-participant in the processes of re-socialisation of women inmates. Through the Critical Discourse Analysis of a semi-structured interview, one identified contradictory meanings attributed to this officer, regarding the process of re-socialisation. By clarifying the details of her daily routine, the meanings of re-socialisation and the responsibility towards the re-socialising process were being built by the interviewee during her discourse. Such responsibility was at times understood as inherent to the job of an officer, at other was identified as being exclusively the prisoners. Despite being made with a simplistic remark, a third aspect was considered by the officer as determinant of the possibilities of the female' re-socialisation: the social issue and the economic context from where
\end{abstract}

Endereço para correspondência: Pontifícia Universidade Católica do Rio Grande do Sul, Av. Ipiranga, 6681, Partenon, Porto Alegre, RS, Brasil 90.619-900. E-mail: mariana.barcinski@pucrs.br 
these women come. Although this criticism had not been fully developed, one understands that the failure or the difficulties inherent to the re-socialising process should also be credited to a social structure which hinders the real possibilities of social re-integration. Therefore, re-socialising would be simultaneously the result of personal effort (both the inmates' and the officers') and of a fairer and more equal social arrangement.

Keywords: Re-socialization, women's prison, correctional officers.

\section{Significados de la Resocialización para las Agentes Penitenciarias en una Cárcel Femenina: Entre el Cuidado y el Control}

\section{Resumen}

El presente estudio objetivó investigar la percepción de una agente penitenciaria acerca de sus atribuciones, especialmente sobre su papel como coparticipé en procesos de resocialización de mujeres privadas de libertad. A través de la Análisis Critica del Discurso de una entrevista semiestructurada, se identifican significados contradictorios atribuidos por esta agente al proceso de resocialización. Al explicitar las particularidades de su día a día de trabajo, los sentidos de la resocialización y la responsabilidad fue por veces entendida como inherente al trabajo del agente penitenciario, en otras fue identificada como exclusivamente de las mujeres encarceladas. Mismo a partir de una critica incipiente, un tercer aspecto fue apuntado por la agente como determinante de las posibilidades de resocialización de las presas: la cuestión social y el contexto socioeconómico de donde las mujeres son provenientes. Mismo que tal critica no haya sido profundizado en el discurso de la participante, entendemos que el fracaso o las dificultades inherentes al proceso resocializador deba también ser acreditado a una estructura social que obstaculiza las posibilidades reales de reinserción social. Por lo tanto, resocializar seria simultáneamente el resultado de esfuerzos personales (de las presas y de las agentes) y de una configuración social mas justa e igualitaria.

Palabra clave: Resocialización, cárcel feminina, agentes penitenciarias.

Em dezembro de 2013 começamos a realizar as entrevistas que compõem parte do trabalho de campo da pesquisa intitulada "Ambiguidades e contradições na prática de cuidar e vigiar das agentes penitenciárias: consequências para a saúde ocupacional". A referida pesquisa era composta por um estudo de delineamento qualitativo, que objetivou investigar o significado do trabalho para agentes penitenciárias que trabalhavam em unidades prisionais exclusivamente femininas do estado do Rio Grande do Sul.

Além do interesse específico pelo trabalho das agentes e pelas relações estabelecidas por estas profissionais dentro das prisões, as entrevistas do estudo qualitativo suscitaram igualmente o interesse pelas dinâmicas estabelecidas em instituições totais (Goffman, 1996). Sua característica total é percebida através das barreiras impostas às relações sociais com o mundo externo. Como instituição total, a prisão configura-se como o local de residência e trabalho daqueles que estão presos, sendo estes separados da sociedade mais ampla por considerável período de tempo, levando uma vida fechada, intensamente controlada e formalmente administrada. A instituição prisão, como enfatiza Fonseca (2006), promove não somente o aprisionamento dos apenados, mas também dos agentes penitenciários, a partir do momento em que estes são submetidos à rotina e à normatização do sistema prisional.

O Estado implicitamente delega ao agente penitenciário a missão de selecionar as condutas adequadas e as medidas corretivas a serem adotadas na prisão, transferindo a responsabilidade de punição dos presos a este agente (Silva, 2009). Para o exercício de suas funções, o agen- 
te deve apreender a dinâmica da convivência no mundo dos cativos, ao mesmo tempo em que deve afirmar constantemente a hierarquia das relações estabelecidas com os indivíduos privados de liberdade.

Sobre os estigmas que marcam a identidade do agente penitenciário, Lourenço (2010) afirma que para a sociedade, em geral, este profissional é considerado desacreditável e potencialmente corruptível, em função de sua proximidade com a delinquência, a marginalidade e a transgressão. Por outro lado, para os presos o agente representa no cotidiano os objetivos institucionais de vigilância e controle, sendo o preso forçado a vivenciar com este uma relação assimétrica de dominação.

Durante a coleta dos dados para a pesquisa acima referida, as entrevistas realizadas evidenciaram o profundo conflito que caracteriza as práticas e, por consequência, as identidades das agentes penitenciárias. Seus discursos expressavam as contradições inerentes a esta profissão, cujas práticas são sustentadas simultaneamente por ideais punitivos e ressocializadores. Segundo Nery (2012) espera-se do agente que ele puna, controle, bem como eduque e ressocialize os presos. Nesta confusão de atribuições se expressa a própria ambiguidade da prisão em sua dupla missão de punir e ressocializar as pessoas privadas de liberdade. Os relatos das agentes expressavam não somente sentimentos contraditórios em relação às presas com quem mantinham contato cotidiano, mas também o conflito óbvio advindo da necessidade de assumir ao mesmo tempo os papéis de agente controlador e ressocializador.

O presente artigo pretende investigar, a partir de um estudo de caso, a percepção de uma agente penitenciária acerca de suas atribuições, especialmente sobre o seu papel como co-participante em processos de ressocialização de mulheres privadas de liberdade. O objetivo é analisar, portanto, a forma como esta agente constrói discursivamente o sentido da ressocialização, entendida como uma das suas atribuições no sistema prisional.

Para aprofundarmos o significado do conflito inerente às práticas dos agentes penitenciá- rios, abaixo delineamos historicamente a noção de ressocialização e de tratamento penal, no sentido de compreendermos a forma como a prisão toma para si a missão corretiva dos transgressores sociais. Trata-se de entender a forma como o conflito individual expresso pelas agentes tem uma trajetória histórica que institui a prisão como espaço simultâneo de controle e de ressocialização.

\section{História da Prisão: Entre o Castigo e o Tratamento Penal}

Segundo Foucault (1975/2010), o sistema jurídico historicamente fundamenta as suas ações em um método coercitivo a serviço da defesa pública e da correção de transgressores da norma social. Até o início do século XVIII, a correção dos transgressores se efetuava através do castigo físico, concretizado no suplício do corpo. Com o objetivo de prover um modelo público de sofrimento, os suplícios visavam a reconstrução da ordem social violada.

Nos séculos XVIII e XIX o espetáculo dos suplícios é substituído pelos procedimentos disciplinares, que caracterizam a transição para um modelo punitivo supostamente mais humanizado. A violação do corpo e sua exposição pública, portanto, dão lugar a formas mais veladas de controle das transgressões, através do isolamento e da privação de liberdades impostos pela prisão. A punição não mais exercida diretamente sobre o corpo físico tem a finalidade de corrigir e reinserir socialmente. A violência, outrora exercida sobre os corpos, atua de maneira não menos incisiva, anulando os desejos e as volições pessoais (Fonseca, 2006).

A história da prisão, historicamente norteada pela dupla missão de punir e corrigir os indivíduos delineia um cenário em que discursos contraditórios permeiam as práticas em seu interior. Fundamentada em sua missão transformadora dos sujeitos, a prisão, com sua "maquinaria carcerária" (Foucault, 1975/2010, p. 208), atua a partir da lógica da coerção e da subordinação.

Segundo Carvalho (2001, p. 111) em um delineamento histórico sobre as penas e sua exe- 
cução, o modelo carcerário brasileiro "funde o suplício do corpo e o adestramento da alma". Portanto, nossa realidade prisional prevê a execução da pena baseada no castigo do corpo físico e nas práticas disciplinares de controle e regulação dos indivíduos a ela submetidos.

Herreira (1995) remonta ao século XVIII a origem da preocupação humanizadora das penas, personificada na figura de Beccaria, precursor da defesa dos direitos humanos dos criminosos. De acordo com a autora, a história testemunha um retrocesso no que diz respeito a este ideal ressocializador da prisão, principalmente até 1945 , quando o direito penal é incumbido da finalidade de proteger o Estado dos dissidentes políticos. A rigidez penal da época, então, contrasta com a defesa dos direitos humanos.

O movimento da Nova Defesa Social, inaugurado na década de 50, consagra a ressocialização como principal objetivo da pena. Segundo o movimento, o objetivo de reinserção social do delinquente, concretizado a partir do tratamento do mesmo, deve nortear a reforma penitenciária. A pena, entendida como forma de castigo, é ressignificada como forma de tratamento, visando adaptar socialmente o criminoso.

$\mathrm{Na}$ legislação brasileira, a Lei de Execuções Penais (LEP; Lei $n^{\circ} 7.210$, 1984), em seu artigo primeiro, elenca como um dos objetivos da execução penal "proporcionar condições para a harmônica integração social do condenado e do internado". A assistência ao preso, no que se refere às suas necessidades de saúde, jurídicas, educacionais, sociais e religiosas é, de acordo com a mesma lei, dever do Estado em sua missão de proporcionar o retorno do apenado ao convívio em sociedade.

Cervini (2002) afirma que entre a segurança e a socialização, o sistema penitenciário moderno optou pela socialização e pela terapia social. Nesta nova concepção de política criminal, a ideia do sofrimento e do castigo foi substituída por outra mais humanizada, baseada na ideologia do tratamento que visa à recuperação do preso para a sociedade. Através de intervenções mais humanizadas, portanto, o tratamento ressocializador busca recuperar o individuo que cometeu alguma infração. Assim, o sistema penitenciário atual passa a ter a promulgada missão de educar e corrigir sujeitos desviantes (Baratta, 1999).

O sistema prisional brasileiro entende a ressocialização dos detentos como uma forma de readequá-los ao convívio social (Santos \& Souza, 2013). Apesar de a LEP afirmar o papel do Estado no tratamento e na inserção social dos apenados, há implícita na concepção de ressocialização a crença de que cabe ao transgressor empreender as mudanças - de valores e de condutas - que supostamente garantirão sua reinserção na sociedade pós-encarceramento. Considerado, portanto, como um movimento de redenção individual, o processo de ressocialização pressuporia o arrependimento pelos delitos/ crimes cometidos e o genuíno desejo pessoal de transformação.

Em um modelo de recuperação focado unicamente no aprisionamento do individuo - e em suas consequências -, parte da responsabilidade pelo sucesso do tratamento efetuado pela prisão é transferida aos servidores do sistema penitenciário, à equipe técnica e aos agentes penitenciários. Após a pena imposta pelo juiz, são estes profissionais que definem as melhores estratégias para educar, corrigir e reinserir o sujeito na sociedade (Wolff, 2005).

Segundo o Art. $5^{\circ}$ da LEP, ao adentrarem o sistema prisional "os condenados serão classificados, segundo os seus antecedentes e personalidade, para orientar a individualização da execução penal". Cabe, então, aos especialistas do sistema - chefes de serviço, psiquiatras, psicólogos e assistentes sociais - a definição do chamado plano individualizador da pena, que fornecerá as diretrizes do cumprimento de cada sentença individual.

Portanto, a individualização do processo que convencionamos chamar de ressocialização dos presos é personificada em indivíduos específicos, deixando intocado o caráter social do processo e das suas possibilidades de êxito. São os presos e os profissionais do sistema que constroem juntos planos individuais visando à reinserção social dos egressos do sistema prisional. 
Desta forma, a consecução satisfatória destes planos, expressa na não reincidência, depende da força de vontade e do desejo de mudança do preso, bem como na capacidade técnica dos profissionais do sistema.

Cervini (2002), no entanto, enfatiza que a ressocialização é um processo que deve considerar simultaneamente o individuo e a sociedade em que ele está inserido. A concepção de tratamento ressocializador focada exclusivamente na figura do individuo transgressor reforça a noção da criminalidade e da transgressão como resultados de um desvio individual. Nesta perspectiva, alguns sujeitos teriam a predisposição natural para o crime, seja por suas características pessoais - biológicas ou psicológicas -, seja pelo impacto do ambiente circundante. As estratégias para reduzir a criminalidade, portanto, seriam voltadas ao individuo, à correção e à adequação de seu comportamento (Baratta, 1999).

Segundo Mello (2014), pretender ressocializar o indivíduo sem avaliar criticamente o meio social no qual se pretende incorporá-lo significa aceitar a ordem social vigente sem questionar sua estrutura e as formas de relação que nela se estabelecem. A autora aponta para a forma como as estruturas sociais têm papel central, tanto nos processos de criminalização de determinados grupos sociais, quanto nas possibilidades de reinserção social dos indivíduos após o cumprimento de suas penas. É neste sentido que qualquer tentativa de ressocialização pressupõe um olhar simultâneo ao individuo que se pretende ver (re)inserido e à sociedade, que deve estar preparada para receber este individuo e se transformar no sentido de propiciar relações menos desiguais em seu âmbito.

Portanto, o processo de ressocialização não deve enfocar exclusivamente a pessoa do apenado, mas sim a relação que este estabelece com a sociedade, para que possamos compreender sua conduta desviante e criminosa. Neste sentido, Sá $(2000$, p. 21) sugere que o termo "reintegração social" seria mais adequado, por reconhecer que o apenado provém de um contexto de marginalização e que o encarceramento representa a oficialização da relação antagônica e excludente estabelecida entre este indivíduo e a esfera social.

Segundo Santos e Souza (2013), o modelo ressocializador que as instituições prisionais propõem é, em sua essência, contraditório. $\mathrm{O}$ detento ao ingressar no sistema prisional tem como incumbência a (re)construção da cidadania e da dignidade, sem que o sistema considere as impossibilidades desta construção em um ambiente totalmente privado de liberdade. Há uma contradição entre o processo de reeducar o homem para a liberdade em um ambiente privado de liberdade e estigmatizado socialmente. Neste sentido, Azevedo, Silva e Barros (2012) afirmam que a prisão não é um lugar ressocializador, uma vez que não reeduca, inclui ou humaniza as pessoas. Assim sendo, a prisão deixa de cumprir seu papel central: ressocializar com a finalidade de oferecer condições de retornar à convivência social adequada. Espera-se que o apenado passe por uma reforma tal que, ao sair, retorne ao convívio social com novos ideais.

Ainda que historicamente as prisões tenham surgido com a finalidade de punição para recuperação moral dos detentos, Rosa (2014) ratifica que este modelo não preenche as necessidades político-sociais de recuperação da população carcerária para o retorno à sociedade. Afastar o sujeito de seu ambiente sem oferecer condições de saúde, trabalho ou de construção de um novo projeto de vida tem resultado no aumento evidente da violência institucional e social, afetando diretamente os índices de reincidência na criminalidade e o consequente aumento da população carcerária. Cervini (2002) aponta que a ressocialização só será possível quando o individuo a ser ressocializado e o encarregado da ressocialização aceitem ou compartilhem o mesmo entendimento acerca da norma social vigente.

Acerca dos impactos negativos do encarceramento, contrários ao promulgado ideal ressocializador da prisão, Wacquant (2004) aponta que a experiência do cárcere serve para aprofundar o quadro de pobreza e isolamento que muitos indivíduos já experimentavam préprisão. Segundo o autor, referindo-se ao contexto 
prisional francês, $60 \%$ dos presos que saem das prisões são desempregados, em comparação com os 50 \% que ingressam na prisão nesta mesma situação.

\section{O Papel da Agente: Entre Ressocializar e Punir}

Uma das questões que tange o fazer da agente penitenciária é a ambiguidade de função. A normatização de suas funções através da legislação e a prática do seu labor cotidiano expressam contradições. Segundo a LEP, o agente deve trabalhar pela ressocialização do interno e prepará-lo para seu retorno à sociedade. Portanto, a instituição prisão, por meio da punição e privação de liberdade, não vai apenas punir o sujeito pelo crime cometido, mas pretende modificá-lo, utilizando a disciplina como mecanismo. Esta dupla missão da prisão - punir e educar - torna as relações estabelecidas entre presos e agentes penitenciários contraditórias e ambivalentes, pois o agente é aquele que oferece apoio e assistência ao preso, no mesmo contexto onde os contém, reprime e pune de forma constante (Fonseca, 2006).

$\mathrm{Na}$ Lei Complementar $\mathrm{N}^{\mathrm{o}} 13.259$, de 20 de outubro de 2009, que dispõe sobre o quadro de servidores penitenciários do Estado do Rio Grande do Sul, as seguintes atribuições são elencadas como pertencentes ao cargo do agente penitenciário: realizar custódia, escolta, disciplina e segurança dos presos; realizar as rondas das alas, galerias, alojamentos, celas, pátios e outras dependências de estabelecimentos prisionais; realizar a revista estrutural das alas, galerias, alojamentos, celas e outras dependências de estabelecimentos prisionais; informar às autoridades competentes sobre as ocorrências; efetuar o controle e a conferência diária da população carcerária em todas as áreas do estabelecimento prisional; supervisionar e fiscalizar o trabalho prisional e a conduta dos presos; realizar os atos e procedimentos das infrações disciplinares.

Nas atribuições citadas, nota-se que o objetivo do trabalho do agente recai sobre a manutenção da ordem e da segurança das instituições penitenciárias, tendo em seu escopo o controle, a vigilância, a custódia, a supervisão e a fiscalização. Ao mesmo tempo em que as funções de controle acima são citadas, há na constituição da lei complementar $\mathrm{N}^{\circ} 13.259$ (2009) elementos que enfatizam a humanização e o papel (re) socializador do agente penitenciário. Neste sentido, o mesmo seria responsável por "assistir, orientar e acompanhar as ações de tratamento penal nos aspectos de atenção e preventivos para socialização do preso" e "orientar e realizar trabalhos ... para instruir os presos em hábitos de higiene, educação e de boas maneiras, despertando o senso de responsabilidade, de dedicação no cumprimento dos deveres familiares, profissionais e sociais".

Nota-se, portanto, uma confusão que denota a dupla função da prisão e, por consequência, do agente penitenciário. Esta ambiguidade de papel vivenciada pelos agentes, de simultaneamente punir e ressocializar, pode ser fator propulsor de dificuldade de posicionamento do agente sobre o seu próprio fazer e, até mesmo, atitudes a serem tomadas diante do preso. O papel de ressocializador torna-se árduo, uma vez que, conforme Wacquant (2004), há um desafio de ressocializar a partir do isolamento, do rompimento de laços afetivos e sociais e de práticas punitivas que revitimizam os presos constantemente.

Retomando as entrevistas realizadas nesta pesquisa, ao versarem sobre seu papel em uma instituição prisional feminina as agentes enfatizaram como função primordial a ressocialização das apenadas. No entanto, seus discursos situam a responsabilidade pelo êxito da ressocialização em atores distintos, construindo a empreitada como resultado de esforços individuais (das presas que desejam se ressocializar), institucionais (delas próprias como agentes ressocializadoras) ou, ainda, sociais (de um preparo da sociedade para receber a egressa do sistema prisional). Neste sentido, o significado da ressocialização adquire contornos mais individualizantes e mais socialmente críticos, resultando em discursos contraditórios. $\mathrm{O}$ fato de estas agentes penitenciárias trabalharem em unidades prisionais exclusivamente femininas dota o entendimento dos processos de ressocialização de características peculiares, marcadas pelo atravessamento de 
questões de gênero e suas expressões no contexto singular de uma instituição total.

A tarefa frequentemente assumida de atuar como principais motivadoras dos processos de recuperação moral das presas é construída através de discursos que enfatizam a suposta habilidade natural das mulheres. Colling (2004) afirma que mulheres são estimuladas para os cuidados dos filhos e os afazeres domésticos, tendo um papel social entrelaçado e subordinado ao cuidado e ao apoio. Tal representação hegemônica do feminino posiciona as mulheres como mais preparadas para o cuidado, a proteção e a educação daqueles ao seu redor, legitimando estas como características essenciais às mulheres. Ao mesmo tempo, a exigência de punição por parte das agentes mulheres e a necessidade de manter-se autoritária frente às presas deve ser altamente desgastante para as mulheres, pois, neste momento, as agentes lançam mão de características associadas ao masculino, como a assertividade e a agressividade (Barcinski, Alternbernd, \& Campani, 2013).

\section{Método}

\section{Delineamento}

Este trabalho configura-se como um estudo de caso, método que nos permite alcançar uma descrição profunda do fenômeno aqui pesquisado, a saber, os significados atribuídos por uma agente penitenciária à ressocialização de mulheres privadas de liberdade. Segundo Stake (2000), a opção por este método se justifica pela crença de que o estudo de um caso particular nos auxiliará na compreensão de um fenômeno mais amplo, fornecendo insights para potenciais generalizações futuras.

A entrevista analisada neste artigo faz parte de um conjunto de 10 entrevistas realizadas entre dezembro de 2013 e janeiro de 2014 nas quatro penitenciárias exclusivamente femininas do Rio Grande do Sul. Estas entrevistas faziam parte de uma pesquisa que tinha por objetivo investigar o cotidiano de trabalho de agentes penitenciárias, enfocando especialmente os aspectos da saúde laboral desta população.
A escolha por analisar especificamente esta entrevista se deve, em primeiro lugar, por acreditarmos que o seu conteúdo reflete, de formas diversas, os dilemas e os conflitos teorizados acerca de suas atribuições profissionais. Além disto, a entrevistada apresentou uma postura crítica em relação a sua atuação, em particular, e sobre a atuação das agentes penitenciárias, em geral. Neste sentido, os dilemas e ambiguidades discutidos teoricamente foram expressos de várias formas no discurso da entrevistada. Vale ressaltar que esta pesquisa cumpriu rigorosamente todos os procedimentos éticos informados pela resolução 466/12 do Conselho Nacional de Saúde, tendo sido aprovada pelo Comitê de Ética em Pesquisa da instituição de ensino superior a qual as pesquisadoras estão vinculadas.

\section{Participante e Instrumento}

A agente penitenciária entrevistada tinha 34 anos e realizava atividades que demandavam o contato direto com as apenadas diariamente. À época da entrevista, Adriana (nome fictício) atuava como agente penitenciária há apenas dois anos, o que em parte pode justificar a postura crítica que ela apresentava sobre a prática das agentes na sua instituição. Além disso, e em contraste com grande parte das mulheres atuando como agentes, ela possuía curso de nível superior em Pedagogia. $\mathrm{Na}$ época em que realizou o concurso, este ainda não era um pré-requisito para assumir o cargo de agente. Adriana trabalhava em uma penitenciária de segurança máxima recém-inaugurada.

A entrevista semiestruturada contou com um roteiro de perguntas conduzidas de maneira flexível e aberta, com o objetivo de que as histórias narradas fossem desenvolvidas com o máximo de abrangência e o mínimo de constrangimento. Tais perguntas versavam sobre a trajetória pessoal e profissional da agente, focando especificamente nos dilemas vivenciados em sua prática profissional cotidiana. A entrevista ora analisada durou cerca de uma hora.

O objetivo da entrevista foi propiciar à agente a possibilidade de relatar, a partir de suas vivências individuais, as eventuais dificuldades 
decorrentes do exercício de sua profissão. De certa forma, a partir dos conflitos vislumbrados na própria descrição das suas atribuições, esperávamos que o seu discurso fosse marcado por ambiguidades e contradições, especialmente ao versar sobre seu cotidiano profissional. Desta forma, buscou-se oferecer um espaço para que Adriana pudesse narrar a forma como atuava, os sentimentos que emergiam desta atuação, as contradições vivenciadas, etc., tendo em vista o papel que lhe é atribuído no contexto carcerário, papel que oscila entre a punição e a ressocialização, como discutido anteriormente. A entrevista foi gravada em áudio, com o consentimento da participante, e transcrita na íntegra para a análise discursiva proposta na pesquisa.

\section{Análise dos Dados}

Para a análise dos dados coletados, utilizou-se como instrumento de investigação a Análise Crítica do Discurso, que tem como objetivo compreender a forma como se dá a relação entre discurso e poder (Van Dijk, 2008). Em síntese, este método de análise busca entender as práticas discursivas como modos de ação historicamente situados. Nesta perspectiva, o discurso é moldado pela estrutura social, e vice-versa (Resende \& Ramalho, 2006). Segundo Fairclough (2008), o discurso deve ser compreendido como forma de prática social, e não como uma produção meramente individual, evidenciando a relação dialética entre discurso e estrutura social. É neste sentido que devemos compreender que o discurso produzido na situação de entrevista por uma agente penitenciária, por exemplo, refletirá o contexto institucional e social ocupado por ela e no qual ela desempenha suas atividades.

\section{Resultados e Discussão}

O foco da análise do discurso da participante recai sobre as formas como ela significa o processo de ressocialização das apenadas. Evidente ao longo da entrevista é que o discurso sobre a ressocialização - sobre suas possibilidades, motivações, dificuldades e obstáculos - confundia-se com a própria descrição das atribuições laborais de Adriana. Em outras palavras, percebeu-se que a tarefa da ressocialização estava intrinsecamente relacionada ao entendimento dela sobre as suas funções cotidianas como agente. Ressocializar as presas, ou auxiliá-las em seu processo pessoal rumo à ressocialização era descrito pela entrevistada como sua obrigação profissional. Portanto, os trechos de discursos analisados versaram sobre a forma como Adriana entende as suas atribuições, afirmando a ressocialização como uma de suas principais.

Os resultados apontam, ainda, para os significados que a entrevistada atribuiu à ressocialização e a quem ela conferiu a responsabilidade sobre a condução do processo ressocializador. Esta responsabilização ora foi associada à própria função de agente penitenciária, ora foi tida como algo que dependia da vontade de mudança das mulheres privadas de liberdade. Questões sociais, tais como a problematização das condições de vida dentro e fora do cárcere também foram elencadas como elementos constituintes das possibilidades ou não da ressocialização.

Os trechos analisados apontam, ainda, para a peculiaridade da posição assumida pela entrevistada como agente penitenciária mulher. Neste sentido, as contradições, ambiguidades e dilemas expressos podem ser resultantes, em grande medida, do fato de Adriana ser uma mulher, cuidando, vigiando e controlando outras mulheres em seu cotidiano de trabalho. Portanto, questões de gênero permeiam as análises ora realizadas, dotando o entendimento desta prática laboral de maior complexidade.

No que tange aos aspectos relacionais que envolvem a prática cotidiana do cargo de agente penitenciária, a entrevistada enfatizou a necessidade de as agentes demarcarem um distanciamento emocional em relação às apenadas, não estabelecendo com elas nenhum tipo de vínculo afetivo. Sustentada por esta crença, Adriana caracterizou sua prática laboral a partir do tratamento indiferenciado concedido às apenadas, enfatizando uma prática pautada pelo reconhecimento de igualdade entre as presas:

. . . eu trato todas como pessoas, e nenhuma é diferente pra mim, tanto que quando as trabalhadoras que podem sair aqui sem algema ... eu não aceito que elas venham 
para atendimento sem algema, se eu que vou lá eu algemo porque ela é presa igual a outra, pra mim nenhum tem privilégio aqui dentro. Eu sempre digo pra elas, elas têm a bermuda que elas ganham, né? E tem umas que cortam ou dobram, eu sempre digo, "tu não é diferente de ninguém aqui dentro, então tu tem que usar que nem as outras, pra mim não tem diferença".

No trecho acima, em que Adriana enfatiza a suposta igualdade no tratamento concedido às apenadas - sejam elas trabalhadoras dentro da prisão ou não -, evidencia-se o rigor de tal tratamento. Paralelamente à indiferenciação no tratamento concedido às presas, Adriana enfatiza o caráter humanizado com que supostamente dota a sua prática como agente: "pra mim são pessoas, não trato elas como presa, porque acho que elas já foram condenadas, aqui dentro pra mim eu trabalho como se eu tivesse trabalhando lá fora, entendeu?"

Se por um lado Adriana se posiciona como aquela que conduz o seu trabalho de forma mais humanitária, por tratar as mulheres privadas de liberdade "como pessoas" e não a partir do estigma usualmente associado às pessoas privadas de liberdade, por outro lado ela expõe a condução de uma prática coercitiva e proibitiva. Isto fica evidente tanto na obrigatoriedade - imposta pela própria Adriana - de que todas as apenadas sejam algemadas ao se dirigirem para os atendimentos, quanto no impedimento de que elas customizem seus uniformes. Este último aspecto concede às mulheres certo arbítrio no que diz respeito à sua apresentação pessoal e representa, em certa medida, uma reação à despersonalização e uniformização impostas pelo cárcere (Cunha, 1994).

A ambiguidade expressa entre o olhar mais humanizado e mais controlador dirigido às mulheres privadas de liberdade ilustra, em parte, o dilema inerente à própria prisão em sua dupla missão de tratar e punir, de cuidar e controlar àquelas submetidas as suas regras e dinâmicas cotidianas (Barcinski et al., 2013).

Ao longo de toda entrevista Adriana buscou diferenciar sua prática daquela desempenhada por outras agentes penitenciárias. No trecho abaixo, o caráter humanizado de seu trabalho foi justificado não a partir de um entendimento de que este olhar deve estar presente na prática cotidiana de agente penitenciária, mas sim como decorrente de um atributo pessoal. Tal atributo é enfatizado ao longo da entrevista como decorrente da formação de Adriana em Pedagogia: "Eu acho que eu tenho um olhar diferenciado por isso, de repente se fosse outra colega veria com outros olhos. Eu não consigo ver elas de outra forma assim que não como pessoa".

$\mathrm{O}$ recurso à individualização do modo de tratamento dispensado, ao mesmo tempo em que situa a participante como fundamentalmente diferente (e melhor) em comparação com a maioria das agentes, sutilmente reafirma a expectativa acerca do trabalho destas profissionais. Em outras palavras, ao enfatizar seu tratamento humanizado, Adriana reforça a imagem socialmente construída das agentes como agressivas, punitivas e coercitivas (Lourenço, 2010).

Adriana expressou em diversos momentos da entrevista a expectativa de reciprocidade por parte das presas, no que se refere ao respeito e ao cuidado por ela dispensados. Por vezes, ao descrever o relacionamento que estabelece no dia a dia com as detentas, a agente ignorou a hierarquia naturalmente existente entre elas, não se reconhecendo como aquela que as controla e as vigia. Demonstrou, portanto, sua frustração quanto à falta de "retorno" por parte das encarceradas, como se a relação estabelecida com estas fosse similar àquela estabelecida entre colegas de trabalho. E é neste sentido, a partir de uma relação dotada de uma artificial simetria, que Adriana espera das presas o reconhecimento por seus esforços humanizadores:

É aquele retorno, elas não entendem, a gente sempre diz assim, elas não tão aqui porque nós queremos, né? Não foi por causa nossa que elas entraram aqui, e às vezes elas ... elas odeiam qualquer uma [qualquer agente], não importa quem é, né?

A expectativa de reciprocidade evidencia o desejo de uma cumplicidade afetiva. Embora sustentando a necessidade de distanciamento emocional, a entrevistada pareceu se ressentir quando este distanciamento parte das próprias apenadas que passam a "não gostar mais" das 
agentes. O discurso de Adriana expressa o desejo de ser bem-quista e reconhecida pelas mulheres privadas de liberdade, especialmente pela forma humanizada com que as trata e como desempenha seu trabalho na instituição.

enquanto tá indo tudo como elas querem tá tudo bem, ai de repente se é uma coisa que não pode, a gente diz um não, elas já não gostam mais de nós, o que não pode não pode, só que dai elas não aceitam.

A expectativa de reciprocidade no afeto dispensado às apenadas contrasta com o distanciamento emocional, anteriormente descrito por Adriana como uma característica fundamental no trabalho de uma agente. A ambiguidade entre o estabelecimento de relações recíprocas de afeto e a necessidade de distanciamento emocional aponta para as particularidades do trabalho efetuado por mulheres agentes. Além do esperado controle e vigilância a serem exercidos sobre as presas, Adriana se refere ao cuidado como parte do seu ofício. Acerca da feminização do trabalho, Marcondes (2013) ressalta que o cuidado, como prática social ancorada na divisão sexual do trabalho, pressupõe uma relação de interdependência entre quem cuida e quem é cuidado. Neste sentido, ao atender às necessidades das apenadas, a participante espera o reconhecimento deste cuidado através do estabelecimento de relações de compreensão e reciprocidade.

Em outros trechos, ao versar sobre as suas atribuições cotidianas, Adriana revestiu sua prática de um sentido potencialmente mais nobre, que não seria, em teoria, pertencente ao cargo de agente penitenciário. A agente relatou assumir as funções de psicóloga, de mãe, de médica, situando as apenadas em posições infantilizadas e intelectualmente inferiores.

porque com a mulher tu tem que ir lá, tué mãe, é psicóloga, é médica, é tudo, é uma criança grande que tá ali, que tu tem que ter paciência, tem que explicar, tem que tentar fazer ela entender que hoje não vai ter o atendimento que ela quer, que ela vai ter que esperar um pouquinho, né?

Abaixo, a entrevistada enfatiza seu papel de cuidado das apenadas recorrendo uma vez mais à infantilização das mesmas:
Eu acho que nosso trabalho, resumindo, a gente é a babá das presas, a gente tem que fazer tudo e cuidar delas, e não foge disso, nosso trabalho resumindo é isso, a gente não pode deixar de prestar um atendimento, levar pra médico, é cuidar delas, né?

Os trechos anteriores refletem uma particularidade importante da cultura prisional, a saber, a infantilização dos cativos (Goffman, 1996). Em seu discurso, Adriana recorrentemente posiciona as agentes como aquelas que precisam aprender a lidar com comportamentos infantis, inadequados e pouco civilizados. Tal como babás e/ou mães, as agentes devem assumir a função de educar e dar limites às presas. Nesse sentido, Adriana descreve as suas atribuições como fundamentadas nas habilidades socialmente esperadas das mães, tais como flexibilidade, assertividade, paciência e carinho.

O cuidado uma vez mais surge como elemento central na descrição das atividades laborais de Adriana. A partir de uma perspectiva de gênero, podemos entender como o cuidado de pessoas - seja no âmbito doméstico ou do trabalho - se constrói socialmente como um elemento definidor do feminino. Yannoulas (2011) enfatiza que atender às necessidades de outras pessoas pressupõe a presença de características supostamente femininas, tais como a docilidade e a paciência. Como doce, paciente, compreensiva e empática, Adriana é capaz de atuar simultaneamente como agente, como mãe, como psicóloga e como amiga das presas.

Paralelamente às funções civilizadoras e corretivas dentro do cárcere, a ressocialização foi identificada por Adriana como uma das maiores funções - se não a principal - do trabalho de agente penitenciário. Em determinados momentos, a entrevistada atribuiu a responsabilidade pela condução do processo ressocializador como inerente à sua função de agente, embora tenha demarcado simultaneamente o caráter individualizante deste processo: "É que é uma coisa que não depende só de nós [a ressocialização das presas], depende mais delas, né?"

Vale notar que a expectativa de Adriana quanto à ressocialização das presas vem associada à existência de uma vontade de mudança por 
parte destas, sem a qual os esforços das agentes não surtiriam efeito. Nesse sentido, ainda que as presas sejam colocadas em uma posição infantilizada e sem autonomia dentro da prisão, segue sendo delas (das presas) a responsabilidade pelas possibilidades de mudança. No trecho abaixo Adriana retorna à ideia de que cabe às presas seguir os conselhos das agentes, como sendo a forma adequada de retomarem suas vidas do lado de fora.

Tem as que entram novas assim, a primeira vez que elas entram e são absolvidas $e$ a gente sempre diz "não voltem mais, não voltem". Já teve uma que disse, que tinha filho, uma guria nova, bonita, dai eu disse "é, agora quando tu sair, vê se vai cuidar da tua filha, né? Retoma tua vida, vai ter uma vida diferente". E dai ela disse assim pra mim, que não, que não valia a pena ela ficar limpando a casa dos outros por um salário, porque ela ganha de 300, 400 reais por hora, entregando droga, então que ela preferia essa vida, e dai eu disse assim "mas e dai vale a pena?"

No trecho anterior, a agente enfatiza a necessidade de as apenadas ouvirem os conselhos das agentes, construídos como a voz da sensatez e da racionalidade em suas orientações às presas. Adriana atribui grande poder ao aconselhamento das agentes no processo de ressocialização. Seria, então, a partir do que as agentes outorgam como certo que a ressocialização poderia se concretizar. Neste sentido, novamente o discurso de Adriana enfatiza a responsabilidade pessoal das presas por seu processo de ressocialização, ao mesmo tempo em que segue as colocando em um papel infantilizado ou moralmente inferior, daquelas que necessitam dos conselhos de pessoas aptas a fornecê-los. Ao prover seus conselhos reabilitadores, a participante se posiciona, ainda, como a guardiã da moralidade das apenadas, função socialmente designada às mães em relação a sua prole (Lewis, 2002).

Adriana faz referência durante a entrevista à presença de um terceiro aspecto determinante das possibilidades de ressocialização das presas: a questão social e o contexto socioeconômico de onde as mulheres privadas de liberdade são pro- venientes. De certo modo, a agente reconhece a precariedade da sociedade em garantir os direitos básicos a essas mulheres, o que contribuiria para a reincidência prisional. Embora sua crítica social não tenha sido contundente ou profundamente fundamentada, ela surge de maneira incipiente no trecho a seguir.

Acho que elas têm que ser bem tratada, para ver a diferença de como elas são tratadas lá fora... Às vezes as pessoas não valorizam, não tratam bem e elas acabam revidando, né? . . Aqui elas têm mais direitos do que a gente quando lá fora, então de repente elas se acham até mais valorizadas aqui dentro, né?

Através da argumentação de que o processo ressocializador encontra obstáculos em uma estrutura social marcada pela ausência de condições mínimas de sobrevivência, Adriana afirma que as mulheres encarceradas seriam possivelmente valorizadas e teriam mais direitos do lado de dentro da prisão.

A afirmação anterior evidencia uma crítica social que complexifica o entendimento do processo ressocializador. Nesse sentido, Adriana credita o fracasso ou as dificuldades a este processo não somente à falta de vontade das presas ou as suas características pessoais, mas faz referência a uma estrutura social que obstaculiza as possibilidades reais de reinserção social. Portanto, se ressocializar seria, no discurso da entrevistada, simultaneamente o resultado de esforços pessoais (das presas e das agentes) e de uma configuração social mais justa e igualitária.

\section{Considerações Finais}

O objetivo deste trabalho foi analisar a forma como uma agente penitenciária constrói discursivamente o sentido da ressocialização, entendida como uma das suas atribuições no sistema prisional. O discurso da participante ora analisado deve ser compreendido como um produto dos atravessamentos inerentes à instituição prisional em sua missão de cuidar e vigiar e de sua trajetória pessoal e profissional. $\mathrm{O}$ discurso de Adriana reflete simultaneamente as particularidades de suas escolhas e crenças, bem como as 
expectativas sociais acerca da atuação das agentes penitenciárias. Expectativas estas que posicionam as agentes mulheres diferentemente dos agentes homens, no que diz respeito à qualidade das interações estabelecidas com as pessoas privadas de liberdade. Se por um lado espera-se dos homens que assumam funções exclusivas de controle, por outro as agentes mulheres incorporam também o cuidado como elemento definidor de suas práticas.

Ao explicitar as especificidades do seu dia-a-dia de trabalho, os sentidos da ressocialização e a responsabilidade diante do processo ressocializador das apenadas são refletidos no discurso da entrevistada. Tal responsabilidade foi entendida recorrentemente como inerente ao trabalho do agente penitenciário. Em outros trechos do discurso da agente, as chances de ressocialização foram identificadas como condicionadas, quase que exclusivamente, à vontade das encarceradas. Em ambos os casos, a importância das detentas seguirem os conselhos dados pelas agentes foi apontada como um fator relevante para a não reincidência. Por fim, a agente tece uma discreta crítica social, ao questionar as possibilidades da ressocialização das mulheres encarceradas em uma estrutura social injusta e despreparada para responder às apenadas e às agentes em seus esforços conjuntos em promover processos ressocializadores.

Para além de buscarmos determinar, através da perspectiva de uma agente penitenciária, a responsabilidade pelo processo de ressocialização dos egressos do sistema prisional, julgamos importante problematizar o próprio conceito de ressocialização. Ao considerarmos a população carcerária feminina e masculina no Brasil, é possível identificarmos, de modo geral, uma população jovem, com baixa escolaridade e proveniente de classes sociais menos favorecidas. Neste sentido, a segregação e o isolamento proporcionados pela experiência do cárcere apenas acirram a condição de marginalização em que tal população vivia pré encarceramento.

A partir deste cenário, questionamos o significado das tentativas de "ressocializar" aqueles que nunca foram igualitariamente inseridos socialmente. Mais urgente do que a busca pela ressocialização, entendida usualmente como o resultado de esforços pessoais de redenção dos apenados, talvez seja a luta pela integração e não exclusão das pessoas que ainda vivem à margem da sociedade. Se entendermos o fenômeno do encarceramento como resultante de um movimento mais complexo de segregação social e econômica, fatalmente teremos que ampliar também o nosso entendimento acerca dos fatores que concorrem para as reais possibilidades de ressocialização.

\section{Referências}

Azevedo, R. O., Silva, M. M., \& Barros, D. M. V. (2012). O papel do agente penitenciário no processo de humanização no presídio do Distrito Federal- Colméia. Projeção, Direito e Sociedade, 3(1), 252-266.

Baratta, A. (1999). Criminologia crítica ao Direito Penal Brasileiro (2. ed.). Rio de Janeiro, RJ: Freitas Bastos.

Barcinski, M., Alternbernd, B., \& Campani, C. (2013). Entre vigiar e punir: Ambiguidades e contradições do agente penitenciário. Ciência \& Saúde Coletiva, 19(7), 2245-2254.

Carvalho, S. (2001). Práticas inquisitivas na execução penal (ou, o aprisionamento do juiz pelos laudos criminológicos: uma abordagem garantista). Doutrina, 1(11), 111-132.

Cervini, R. (2002). Os processos de descriminalização. São Paulo, SP: Revistas dos Tribunais.

Colling, A. M. (2004). O corpo que os gregos inventaram. In M. N. Strey \& S. T. L. Cabeda (Eds.), Corpos e subjetividades em exercício interdisciplinar (pp. 49-64). Porto Alegre, RS: Editora Universitária da Pontifícia Universidade Católica do Rio Grande do Sul.

Cunha, M. I. P. (1994). Malhas que a reclusão tece. Questões de identidade numa prisão feminina. Lisboa: Gabinete de Estudos Jurídico-Sociais.

Fairclough, N. (2008). Discurso e mudança social. Brasília, DF: Universidade de Brasília.

Fonseca, K. P. (2006). Re(Pensando) o crime como uma relação de antagonismo entre seus autores e a sociedade. Psicologia: Ciência e Profissão, 26(4), 532-547. 
Foucault, M. (2010). Vigiar e punir: O nascimento da prisão. Petrópolis, RJ: Vozes. (Original publicado em 1975)

Goffman, E. (1996). Manicômios, Prisões e Conventos. São Paulo, SP: Perspectiva.

Herreira, A. S. (1995). Nova defesa social. Akrópolis, 3(12), 20-25.

Lei Complementar $\mathrm{n}^{\mathrm{o}} 13.259$, de 20 de Outubro de 2009. (2009). Recuperado em http://www.al.rs. gov.br/legiscomp/arquivo.asp?Rotulo=Lei $\% 20$ Complementar \% 20 n \% C $2 \%$ B A \% 20 13259\&idNorma $=990 \&$ tipo $=$ pdf

Lei $\mathrm{n}^{\circ} 7.210$, de 11 de julho de 1984. (1984). Lei de Execução Penal. Recuperado em http://www. planalto.gov.br/ccivil_03/leis/17210.htm

Lewis, S. (2002). Concepts of motherhood. In H. Klee, M. Jackson, \& S. Lewis (Eds.), Drug misuse and motherhood (pp. 32-44). London: Routledge.

Lourenço, L. C. (2010). Batendo a tranca: Impactos do encarceramento em agentes penitenciários da Região Metropolitana de Belo Horizonte. Dilemas: Revista de Estudos de Conflito e Controle Social, 3(10), 11-31.

Marcondes, M. M. (2013). O cuidado na perspectiva da divisão sexual do trabalho: Contribuições para os estudos sobre a feminização do mundo do trabalho. In S. C. Yannoulas (Ed.), Trabalhadoras: Análise da feminilização das profissões e ocupações (pp. 251-279). Brasília, DF: Abaré.

Mello, D. C. D. (2014). A prisão feminina: Gravidez e maternidade: Um estudo da realidade em Porto Alegre-RS/Brasil e Lisboa/Portugal (Tese de doutorado, Ciências Criminais, Pontifícia Universidade do Rio Grande do Sul, Porto Alegre, RS, Brasil).

Nery, T. R. A. (2012). Da ética à poética do ser servidor penitenciário. Porto Alegre, RS: Companhia Rio-Grandense de Artes Gráficas.
Resende, V. M., \& Ramalho, V. (2006). Análise de discurso crítica. São Paulo, SP: Contexto.

Rosa, S. M. (2014). Instituições prisionais: Atenção psicossocial, saúde mental e reinserção social. Fragmentos de Cultura, 24(1), 125-138.

Sá, A. A. (2000). Algumas ponderações acerca da reintegração social dos condenados à pena preventiva de liberdade. Esmape, 5(11), 25-70.

Santos, T. S., \& Souza, S. B. (2013). Da condição de "ressocialização" dos egressos do sistema prisional. Café com Sociologia, 2(3), 25-35.

Silva, R. M. (2009). O papel do agente penitenciário na prevenção da violência. Recuperado em http://agepensczs.blogspot.com.br/2011/04/o-papel-do-agente-penitenciario-na.html

Stake, R. E. (2000). Case studies. In N. K. Denzin \& Y. S. Lincoln (Eds.), Handbook of qualitative research (pp. 435-454). London: Sage.

Van Dijk, T. A. (2008). Discurso e poder. São Paulo, SP: Contexto.

Wacquant, L. (2004). A aberração carcerária à moda francesa. Revista de Ciências Sociais, 47(2), 215-232.

Wolff, M. P. (2005). Antologia de vidas e histórias na prisão: Emergência e Injunção de Controle Social. Rio de Janeiro, RJ: Lumen Juris.

Yannoulas, S. (2011). Feminização ou feminilização? Apontamentos em torno de uma categoria. Temporalis, 11(22), 271-292.
Recebido: 09/02/2016

$1^{a}$ revisão: $24 / 06 / 2016$ Aceite final: 05/07/2016 